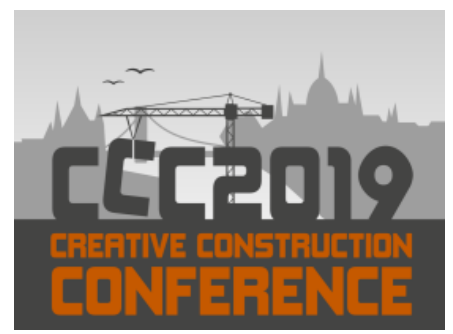

Available online at 2019.creative-construction-conference.com/proceedings/

CCC 2019

Proceedings of the Creative Construction Conference (2019) 090

Edited by: Miroslaw J. Skibniewski \& Miklos Hajdu

https://doi.org/10.3311/CCC2019-090

Creative Construction Conference 2019, CCC 2019, 29 June - 2 July 2019, Budapest, Hungary

\title{
Clients and construction health and safety $(\mathrm{H} \& S)$
}

\author{
John Smallwood
}

Department of Contruction Management, Nelson Mandela University, Port Elizabety, 6001, South Africa

\begin{abstract}
Contractor H\&S is influenced directly and indirectly by clients. Furthermore, traditionally, worldwide, better practice client organisations have maintained rigorous contractor H\&S management programmes and contributed to contractor H\&S.

Given the above, a self-administered questionnaire survey was conducted among developer members of the South African Property Owners Association's (SAPOA) to determine construction H\&S perceptions and practices.

Findings include: clients view the traditional project parameters of time, quality, and cost as more important than public H\&S and project H\&S; client organisations can be deemed to have influenced and contributed to contractors' H\&S relative to a range of interventions / requirements; clients appoint agents to fulfil their function in terms of the Construction Regulations; a range of design, procurement, and construction aspects impact on H\&S; a range of benefits accrue from client contributions to contractor $\mathrm{H} \& \mathrm{~S}$; clients contend that they have influenced construction H\&S, and that they could influence construction H\&S more, and a range of design, procurement and construction aspects / interventions can contribute to an improvement in construction $H \& S$.

Conclusions include that clients do influence construction H\&S and that multi-stakeholder benefits accrue there from, and that clients can further contribute to construction H\&S. Furthermore, the client related requirements of the Construction Regulations are underscored by the findings.
\end{abstract}

Recommendations include that property and other built environment tertiary education related programmes should address construction H\&S, and SAPOA and other professional associations should evolve construction H\&S practice notes.

(C) 2019 The Authors. Published by Budapest University of Technology and Economics \& Diamond Congress Ltd.

Peer-review under responsibility of the scientific committee of the Creative Construction Conference 2019.

Keywords: Clients; Construction; Health and Safety

\section{Introduction}

The report 'Construction Health \& Safety Status \& Recommendations' highlighted the considerable number of accidents, fatalities, and other injuries that occur in the South African construction industry [1]. The report cited the high-level of non-compliance with H\&S legislative requirements, which is indicative of a deficiency of effective management and supervision of $\mathrm{H} \& \mathrm{~S}$ on construction sites as well as planning from the inception / conception of

*Corresponding author: Author email: john.smallwood@mandela.ac.za 
John Smallwood / Proceedings of the Creative Construction Conference (2019) 090 https://doi.org/10.3311/CCC2019-090

projects within the context of project management. The report also cited a lack of sufficiently skilled, experienced, and knowledgeable persons to manage $\mathrm{H} \& \mathrm{~S}$ on construction sites.

Within the context of South Africa, the Construction Regulations promulgated in July 2003, and amended in 2014 [2], effectively included client responsibility for construction H\&S. Given this a study was conducted to assess clients' construction H\&S perceptions and practices, the primary objective of the study being to determine the role of clients in contractor H\&S and their influence thereon. The secondary objectives of the study being to determine the:

- Importance of project parameters to client organisations;

- Extent to which client organisations influence and contribute to contractors' H\&S;

- Extent to which various aspects negatively impact on construction H\&S;

- Extent to which respondents' organisations have influenced construction H\&S, and the extent to which it could influence construction $\mathrm{H} \& \mathrm{~S}$;

- Extent to which benefits have resulted from clients' contributions to contractor H\&S, and

- Extent to which various aspects / interventions can contribute to an improvement in construction H\&S.

\section{Review of the Literature}

\subsection{Compliance and non-compliance}

According to the Construction Industry Development Board (cidb) [1], during August 2007, the Department of Labour inspectorate conducted inspections throughout South Africa. 1415 construction sites were visited and 52.5\% of the contractors were found to be non-compliant with the Occupational Health \& Safety Act and the Construction Regulations. Of the 1388 notices issued by inspectors, $86(6 \%)$ were improvement notices, 1015 (73\%) were contravention, and 287 (21\%) were prohibition. These findings indicate contractors in general are not complying. Furthermore, they underscore the rationale for client responsibility for construction $\mathrm{H} \& \mathrm{~S}$ in terms of the Construction Regulations and the moral need for clients to contribute to construction H\&S.

\subsection{Cost of Accidents (COA)}

The cidb [1] refers to Smallwood's 2004 findings that the total COA could have been between $4.3 \%$ and 5.4\%, based upon the value of construction work completed in South Africa in the year 2002. The key issue relative to the COA is that ultimately, clients incur the COA as the COA is included in contractors' cost structures, and therefore constitutes a motivator to clients to contribute to construction $\mathrm{H} \& \mathrm{~S}$.

\subsection{Recommendations and legislation pertaining to clients}

The International Labour Office (ILO) [3] states clients should:

- Coordinate or nominate a competent person to coordinate all activities relating to $\mathrm{H} \& \mathrm{~S}$ on their construction projects;

- Inform all contractors on such projects of special risks to H\&S that they are aware of, and

- Require tenderers to make provision for the cost of H\&S measures during the construction process.

The Construction Regulations [2] require a range of client interventions relative to contractors. In terms of information they must prepare and provide Principal Contractors (PCs) with H\&S specifications, and any information that may affect H\&S. In terms of procurement they must ensure that PCs have made provision for the cost of H\&S in their tenders, that they are competent, have the necessary resources, have workers' compensation insurance cover, and they must appoint them in writing. In terms of planning and controlling, they must discuss the contents of and approve the 
John Smallwood / Proceedings of the Creative Construction Conference (2019) 090 https://doi.org/10.3311/CCC2019-090

H\&S plan, which is the PC's response to the H\&S specification, ensure that the PC implements and maintains the H\&S plan, and stop work not in accordance with the H\&S plan. Therefore, clients are legally required to become directly and indirectly involved in, and to contribute to contractor H\&S. However, clients may appoint an agent in terms of the responsibilities, but the agent must be registered, competent, and have the necessary resources to fulfill the function of agent.

\subsection{Client actions}

A model evolved by Huang and Hinze [4] indicates that clients influence project H\&S through: communicating H\&S; selection, and participating in $\mathrm{H} \& \mathrm{~S}$ management. Communicating $\mathrm{H} \& \mathrm{~S}$ includes setting the project expectations for every party involved through the contract and other communications. Selection includes the: selection of contract type and arrangement; project design; project schedule; construction methods; selection of designers, contractors, and subcontractors, and decisions regarding outsourcing and vendors. Participating includes: H\&S program; H\&S orientation; H\&S observations; H\&S inspections; accident investigations; H\&S recognition; H\&S enforcement; drug testing; job $H \& S$ analysis, and $H \& S$ plan review.

The Australian Federal Safety Commissioner's best practice client H\&S principles emphasises client involvement in and contributions to contractor H\&S [5]: developing an H\&S culture in their own organisations and across the construction industry by including $\mathrm{H} \& \mathrm{~S}$ as an integral aspect of project management; affording $\mathrm{H} \& \mathrm{~S}$ status equal to that afforded cost, quality, and time; providing leadership and commitment by considering $\mathrm{H} \& \mathrm{~S}$ at every level of decision making; referring to $\mathrm{H} \& \mathrm{~S}$ standards in contracts; monitoring $\mathrm{H} \& \mathrm{~S}$ throughout all stages of projects; communicating $\mathrm{H} \& \mathrm{~S}$ information to all project stakeholders in the supply chain, and managing $\mathrm{H} \& \mathrm{~S}$ hazards and risks, and maintaining effective $H \& S$ measures across the project lifecycle. This in turn requires regular H\&S reporting using both 'leading' and 'lagging' H\&S indicators, the conducting of project completion reviews that address H\&S, and monitoring and evaluating H\&S performance through Key Performance Indicators (KPIs) to measure performance against industry, organisational, and project benchmarks.

\subsection{Benefits of client involvement}

According to the Health \& Safety Executive (HSE) [6], where clients demand high H\&S standards on their projects, these are achieved, and argue that there are good business and ethical reasons for clients to be committed to H\&S. Accidents may implicate clients and result in delays. Furthermore, unhappy workers produce defective work, and ultimately clients pay for all the resultant unavoidable waste.

Hinze [7] cites a specific case study involving a large public sector client in the USA, which client made a dramatic change in the H\&S performances of its contractors in a period of just two years. Although the client was proactive relative to $H \& S$, they were possibly not as proactive as they could have been. Further, although the H\&S performance of the contractors on the client's projects was regarded as respectable given an average recordable injury rate (RIR) of 4.2 , as a result of a fatality on a project the client met with contractors to express their H\&S expectations. The primary changes made by contractors included increased worker H\&S training, increased supervisor H\&S training, random drug testing, bolstered H\&S staffing of projects, more detailed accident investigations, and a stronger focus by the client on subcontractor management. Furthermore, the client required the top managers of the contractors to show their commitment to $\mathrm{H} \& \mathrm{~S}$ and to indicate the importance of $\mathrm{H} \& \mathrm{~S}$ within the organisations. As a result of these interventions the RIR dropped from 4.2 to 2.34 .

\section{Research}

\subsection{Research method and sample stratum}

The sample stratum consisted of members of the South African Property Owners Association (SAPOA). 75 Members that undertook developments were surveyed using a self-administered questionnaire. The questionnaire consisted of 
John Smallwood / Proceedings of the Creative Construction Conference (2019) 090 https://doi.org/10.3311/CCC2019-090

twelve closed-ended questions. Nine of the questions required responses to a five-point Likert type scale, one required a 'Yes' or 'No' response, one required the selection of possible approaches, and one required the provision of data. Two members responded stating that they were not involved with development, and two questionnaire surveys were returned to the sender as they could not be delivered. 13 responses were included in the analysis of the data, which constitutes a net response rate of $18.3 \%: 13 /(75-4)$.

\subsection{Research findings}

Table 1 indicates the importance of seven parameters to clients in terms of percentage responses to a scale of 1 (not important) to 5 (very important), and a mean score (MS) ranging between 1.00 and 5.00. It is notable that the MSs are all above the midpoint score of 3.00, which indicates that in general the respondents can be deemed to perceive the parameters as important. However, given that the MSs for the top six parameters are $>4.20 \leq 5.00$, the respondents can be deemed to perceive them to be between more than important to very important / very important. It is notable that all three of the traditional project parameters, are ranked within the top three, the implication being that clients are likely to focus on these parameters, particularly when faced with challenges relative thereto. Construction ergonomics falls within the range $>3.40 \leq 4.20$ - between important to more than important / more than important.

Table 1. Importance of project parameters to respondents' organisations.

\begin{tabular}{|c|c|c|c|c|c|c|c|c|}
\hline \multirow{3}{*}{ Parameter } & \multicolumn{6}{|c|}{ Response (\%) } & \multirow{3}{*}{ MS } & \multirow{3}{*}{ Rank } \\
\hline & \multirow{2}{*}{$\begin{array}{l}\text { Un- } \\
\text { sure }\end{array}$} & \multicolumn{3}{|c|}{ Not.. } & \multicolumn{2}{|c|}{ Very } & & \\
\hline & & 1 & 2 & 3 & 4 & 5 & & \\
\hline Project time & 0.0 & 0.0 & 0.0 & 0.0 & 15.4 & 84.6 & 4.85 & 1 \\
\hline Project quality & 0.0 & 0.0 & 0.0 & 7.7 & 7.7 & 84.6 & 4.77 & 2 \\
\hline Project cost & 0.0 & 0.0 & 0.0 & 0.0 & 30.8 & 69.2 & 4.69 & 3 \\
\hline Public H\&S & 0.0 & 0.0 & 7.7 & 7.7 & 7.7 & 76.9 & 4.54 & 4 \\
\hline Project H\&S & 0.0 & 0.0 & 7.7 & 0.0 & 30.8 & 61.5 & 4.46 & 5 \\
\hline Environment & 0.0 & 0.0 & 0.0 & 23.1 & 30.8 & 46.2 & 4.23 & 6 \\
\hline Construction ergonomics & 0.0 & 7.7 & 0.0 & 7.7 & 76.9 & 7.7 & 3.77 & 7 \\
\hline
\end{tabular}

Table 2 indicates the extent to which respondents' organisations influence and contribute to contractors' H\&S relative to twenty-three interventions / requirements in terms of percentage responses to a scale of never to always, and a MS ranging between 1.00 and 5.00. It is notable that nineteen of the MSs are above the midpoint score of 3.00, which indicates that in general the respondents' organisations can be deemed to have influenced and contributed to contractors' H\&S relative to the interventions / requirements. However, given that the MSs for the top seven interventions / requirements are $>4.20 \leq 5.00$, the respondents can be deemed to perceive the influence and contribution to be between often to always / always. However, 'require a project $\mathrm{H} \& \mathrm{~S}$ plan of contractors', 'provide a project H\&S specification to contractors', and 'ensure contractor's registration for compensation insurance' are requirements of the Construction Regulations. Although clients are also required to ensure that contractors have made adequate financial allowance for $\mathrm{H} \& \mathrm{~S}$, 'require inclusion of an $\mathrm{H} \& \mathrm{~S}$ section in the Bill of Quantities / contract documentation' constitutes best practice. 'Require a contractor H\&S management system' also constitutes best practice. 'Specify materials i.e. instruct designers' and 'conduct constructability reviews of design' are notable rankings as they indicate client focus on design related issues that influence H\&S. The interventions / requirements ranked eighth to fifteenth have mean scores $>3.40 \leq 4.20$, which indicates that respondents can be deemed to perceive the influence and contribution to be between sometimes to often / often. 'Provide contractor H\&S guidelines' , ' contractor H\&S coordinator' , 'provide H\&S induction' , and 'require attendance of client H\&S meetings', constitute direct client H\&S interventions and best practice. 'Review designer design and construction method statements' indicates client focus on a design related intervention that influences H\&S and which is also a requirement of the Construction Regulations. 'Require risk assessments', 'require method statements', and 'require safe work procedures (SWPs)' are requirements of the Construction Regulations. The interventions / requirements ranked 
John Smallwood / Proceedings of the Creative Construction Conference (2019) 090 https://doi.org/10.3311/CCC2019-090

sixteenth to twenty-first have mean scores $>2.60 \leq 3.40$, which indicates that respondents can be deemed to perceive the influence and contribution to be between rarely to sometimes / sometimes. Ensure adequate contractor financial allowance for H\&S' is a requirement of the Construction Regulations. 'Review contractor H\&S meeting minutes', 'require permit to work', 'require employee identification', 'pre-qualify contractors on H\&S', and provide $\mathrm{H} \& \mathrm{~S}$ training to contractors. Twenty-second ranked 'require MSDSs' has a mean score $>1.80 \leq 2.60$, which indicates that respondents can be deemed to perceive the influence and contribution relative thereto to be between never to rarely / rarely, and relative to twenty-third ranked provide $H \& S$ incentives to be between never to rarely. MSDSs are required in terms of the Regulations for Hazardous Chemical Substances and 'provide H\&S incentives' is a client best practice intervention.

Table 2. Extent to which respondents' organisations influence and contribute to contractors' H\&S.

\begin{tabular}{|c|c|c|c|c|c|c|c|c|}
\hline \multirow[b]{2}{*}{ Intervention / Requirement } & \multicolumn{6}{|c|}{ Response (\%) } & \multirow[b]{2}{*}{ MS } & \multirow[b]{2}{*}{ Rank } \\
\hline & 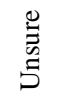 & 离 & 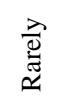 & 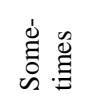 & 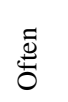 & 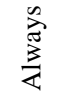 & & \\
\hline Require a project $\mathrm{H} \& \mathrm{~S}$ plan of contractors & 0.0 & 0.0 & 0.0 & 7.7 & 0.0 & 92.3 & 4.85 & 1 \\
\hline $\begin{array}{l}\text { Require inclusion of an H\&S section in the Bill of Quantities / } \\
\text { Contract documentation }\end{array}$ & 0.0 & 0.0 & 7.7 & 0.0 & 7.7 & 84.6 & 4.69 & $2=$ \\
\hline Require a contractor $\mathrm{H} \& \mathrm{~S}$ management system & 0.0 & 0.0 & 0.0 & 7.7 & 23.1 & 69.2 & 4.62 & $2=$ \\
\hline Provide a project H\&S specification to contractors & 0.0 & 0.0 & 7.7 & 7.7 & 23.1 & 61.5 & 4.38 & 4 \\
\hline Specify materials i.e. instruct designers & 0.0 & 0.0 & 0.0 & 15.4 & 46.2 & 38.5 & 4.23 & $5=$ \\
\hline Conduct constructability reviews of design & 0.0 & 0.0 & 7.7 & 7.7 & 38.5 & 46.2 & 4.23 & $5=$ \\
\hline Ensure contractors' registration for compensation insurance & 0.0 & 7.7 & 7.7 & 7.7 & 7.7 & 69.2 & 4.23 & $5=$ \\
\hline Provide contractor $\mathrm{H} \& \mathrm{~S}$ guidelines & 0.0 & 0.0 & 23.1 & 0.0 & 23.1 & 53.8 & 4.08 & 8 \\
\hline Contractor H\&S Coordinator & 0.0 & 7.7 & 7.7 & 7.7 & 30.8 & 46.2 & 4.00 & $9=$ \\
\hline Require risk assessments & 0.0 & 15.4 & 0.0 & 7.7 & 23.1 & 53.8 & 4.00 & $9=$ \\
\hline Review designer 'design and construction' method statements & 0.0 & 0.0 & 7.7 & 23.1 & 46.2 & 23.1 & 3.85 & $11=$ \\
\hline Provide client $\mathrm{H} \& \mathrm{~S}$ induction & 0.0 & 7.7 & 23.1 & 0.0 & 15.4 & 53.8 & 3.85 & $11=$ \\
\hline Require method statements & 0.0 & 0.0 & 15.4 & 30.8 & 23.1 & 30.8 & 3.69 & $13=$ \\
\hline Require safe work procedures (SWPs) & 7.7 & 7.7 & 7.7 & 7.7 & 23.1 & 46.2 & 3.69 & $13=$ \\
\hline Require attendance of client $\mathrm{H} \& \mathrm{~S}$ meetings & 0.0 & 15.4 & 15.4 & 7.7 & 23.1 & 38.5 & 3.54 & 15 \\
\hline Ensure adequate contractor financial allowance for $\mathrm{H} \& S$ & 7.7 & 15.4 & 7.7 & 7.7 & 23.1 & 38.5 & 3.38 & 16 \\
\hline Review contractor $\mathrm{H} \& \mathrm{~S}$ meeting minutes & 0.0 & 15.4 & 15.4 & 30.8 & 7.7 & 30.8 & 3.23 & 17 \\
\hline Require permit to work & 7.7 & 15.4 & 15.4 & 15.4 & 7.7 & 38.5 & 3.15 & 18 \\
\hline Require employee identification & 0.0 & 23.1 & 15.4 & 23.1 & 7.7 & 30.8 & 3.08 & 19 \\
\hline Pre-qualify contractors on $\mathrm{H} \& \mathrm{~S}$ & 0.0 & 30.8 & 23.1 & 0.0 & 15.4 & 30.8 & 2.92 & 20 \\
\hline Provide $\mathrm{H} \& \mathrm{~S}$ training to contractors & 0.0 & 30.8 & 30.8 & 7.7 & 0.0 & 30.8 & 2.69 & 21 \\
\hline Require material safety data sheets (MSDSs) & 7.7 & 38.5 & 7.7 & 15.4 & 23.1 & 7.7 & 2.31 & 22 \\
\hline Provide $\mathrm{H} \& \mathrm{~S}$ incentives & 7.7 & 53.8 & 30.8 & 0.0 & 7.7 & 0.0 & 1.46 & 23 \\
\hline
\end{tabular}

$84.6 \%$ of respondents' organisations appoint agents to fulfill their function in terms of the Construction Regulations. $7.7 \%$ were unsure and $7.7 \%$ meet the requirements through in-house personnel and agents. This finding indicates that clients are likely to lack the requisite competencies.

Table 3 indicates the extent to which twelve aspects negatively impact on construction $\mathrm{H} \& \mathrm{~S}$ in terms of percentage responses to 'does not' and a scale of 1 (minor) to 5 (major), and a MS ranging between 0.00 and 5.00. It is notable that $11 / 12(91.7 \%)$ MSs are above the midpoint score of 2.50, which indicates that in general the respondents can be deemed to appreciate the extent to which aspects negatively impact on construction H\&S. The top seven ranked MSs 
John Smallwood / Proceedings of the Creative Construction Conference (2019) 090 https://doi.org/10.3311/CCC2019-090

are $>3.33 \leq 4.17$, and thus the respondents can be deemed to perceive the extent to be between some extent to a near major extent / near major extent. QMSs complement H\&S as they engender quality assurance. Contractor registration complements overall performance and $\mathrm{H} \& \mathrm{~S}$, particularly if $\mathrm{H} \& \mathrm{~S}$ is included among the criteria to register. Management commitment and worker participation are the 'two pillars' of an H\&S programme, and therefore management and worker H\&S competencies are important. H\&S culture occurs upstream of management system, exposure, and incidents, and therefore a poor or non-existent $\mathrm{H} \& \mathrm{~S}$ culture negatively affects $\mathrm{H} \& \mathrm{~S}$. Reference to $\mathrm{H} \& \mathrm{~S}$ in standard contract documentation promotes attention to $\mathrm{H} \& \mathrm{~S}$ and engenders financial provision. $\mathrm{H} \& \mathrm{~S}$ management systems create the framework within which $\mathrm{H} \& \mathrm{~S}$ can be managed and they essentially assure healthy and safe work. The aspects ranked seventh to eight have MSs $>2.50 \leq 3.33$ - between a near minor to some extent / some extent. Separation of design and construction marginalises H\&S as construction H\&S knowledge and expertise is not transferred. Shortened project duration invariably results in the introduction of additional resources into the workplace and often the scope and value of the works being simply incompatible with the available time. H\&S needs to be resourced due to the various related interventions and thus needs to be budgeted for - inadequate financial resources are often cited as the reason for not addressing $\mathrm{H} \& \mathrm{~S}$. A related issue is that of competitive tendering, which research has identified as being a barrier to $\mathrm{H} \& \mathrm{~S}$ as should a committed contractor make the requisite allowance for $\mathrm{H} \& \mathrm{~S}$ they are likely to lose the bid to a less committed contractor. The MS of last ranked H\&S pre-qualification falls within the range $>1.67 \leq 2.50$ - between a minor extent to a near minor extent / near minor extent. $\mathrm{H} \& \mathrm{~S}$ pre-qualification has shown to positively affect construction H\&S.

Table 3. Extent to which various aspects negatively impact on construction H\&S.

\begin{tabular}{|c|c|c|c|c|c|c|c|c|c|}
\hline \multirow{3}{*}{ Aspect } & \multicolumn{7}{|c|}{ Response (\%) } & \multirow{3}{*}{ MS } & \multirow{3}{*}{ Rank } \\
\hline & \multirow{2}{*}{$\begin{array}{l}\text { Un- } \\
\text { sure }\end{array}$} & \multirow{2}{*}{$\begin{array}{l}\text { Does } \\
\text { not }\end{array}$} & \multicolumn{5}{|c|}{ 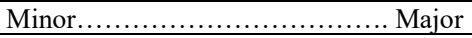 } & & \\
\hline & & & 1 & 2 & 3 & 4 & 5 & & \\
\hline Lack of quality management systems (QMSs) & 0.0 & 0.0 & 0.0 & 0.0 & 7.7 & 76.9 & 15.4 & 4.08 & 1 \\
\hline Lack of contractor registration & 23.1 & 0.0 & 0.0 & 7.7 & 7.7 & 38.5 & 23.1 & 4.00 & 2 \\
\hline Lack of management $\mathrm{H} \& \mathrm{~S}$ competencies & 0.0 & 0.0 & 7.7 & 7.7 & 7.7 & 61.5 & 15.4 & 3.69 & $3=$ \\
\hline Lack of worker H\&S competencies & 0.0 & 0.0 & 7.7 & 7.7 & 7.7 & 61.5 & 15.4 & 3.69 & $3=$ \\
\hline H\&S culture & 0.0 & 0.0 & 0.0 & 25.0 & 8.3 & 41.7 & 25.0 & 3.67 & 5 \\
\hline $\begin{array}{l}\text { Inadequate reference to } \mathrm{H} \& \mathrm{~S} \text { in standard contract } \\
\text { documentation }\end{array}$ & 7.7 & 0.0 & 7.7 & 7.7 & 15.4 & 46.2 & 15.4 & 3.58 & 6 \\
\hline Lack of H\&S management systems (H\&SMSs) & 0.0 & 0.0 & 15.4 & 7.7 & 7.7 & 61.5 & 7.7 & 3.38 & 7 \\
\hline Separation of design and construction & 7.7 & 0.0 & 15.4 & 7.7 & 23.1 & 38.5 & 7.7 & 3.17 & 8 \\
\hline Shortened project duration & 0.0 & 8.3 & 16.7 & 8.3 & 16.7 & 25.0 & 25.0 & 3.08 & $9=$ \\
\hline Inadequate financial resources & 0.0 & 7.7 & 15.4 & 7.7 & 15.4 & 38.5 & 15.4 & 3.08 & $9=$ \\
\hline Competitive tendering & 0.0 & 0.0 & 15.4 & 30.8 & 23.1 & 15.4 & 15.4 & 2.85 & 11 \\
\hline Lack of H\&S pre-qualification & 7.7 & 0.0 & 30.8 & 15.4 & 30.8 & 7.7 & 7.7 & 2.42 & 12 \\
\hline
\end{tabular}

Respondents were required to indicate the extent to which their organisations have influenced construction $\mathrm{H} \& \mathrm{~S}$, and the extent to which they could influence construction $\mathrm{H} \& \mathrm{~S}$ on a scale of 1 (minor) to 5 (major). The 'have influenced' MS is 3.42, and the 'could influence' MS is 4.00. Given that the MSs are $>3.33 \leq 4.17$, the respondents can be deemed to perceive the extent to be between some extent to a near major extent / near major extent. These are notable findings in that, firstly, clients recognise the potential to further influence construction H\&S. Secondly, the perception on the part of clients that they could influence construction H\&S is likely to be attributable to them having influenced it, and the realisation that improvements accrue from contributing to contractors' $\mathrm{H} \& \mathrm{~S}$.

Table 4 indicates the extent to which improvements have resulted from respondents' organisations' contributions to contractor H\&S in terms of percentage responses to a scale of 'No' and 1 (minor) to 5 (major), and a MS ranging between 0.00 and 5.00. All the MSs are above the midpoint score of 2.50, which indicates that in general the respondents can be deemed to perceive that the improvements have been realised. The top two ranked MSs are > 3.33 
John Smallwood / Proceedings of the Creative Construction Conference (2019) 090 https://doi.org/10.3311/CCC2019-090

$\leq 4.17$, and thus the respondents can be deemed to perceive the extent to be between some extent to a near major extent / near major extent. The aspects ranked joint third to ninth fall within the range $>2.50 \leq 3.33$ - between a near minor to some extent / some extent. These findings are important as they confirm the benefits to clients of contributing to contractor H\&S, which benefits are likely to reinforce clients' focus on H\&S and the inclusion of it as a value on projects. Furthermore, the findings confirm the synergy between $H \& S$ and the environment, productivity, quality, and time.

Table 4. Extent to which improvements have resulted from respondents' organisations' contributions to contractor H\&S.

\begin{tabular}{|c|c|c|c|c|c|c|c|c|c|}
\hline \multirow{3}{*}{ Improvement } & \multicolumn{7}{|c|}{ Response (\%) } & \multirow{3}{*}{ MS } & \multirow{3}{*}{ Rank } \\
\hline & \multirow{2}{*}{$\begin{array}{l}\text { Un- } \\
\text { sure }\end{array}$} & \multirow{2}{*}{ No } & \multicolumn{5}{|c|}{ 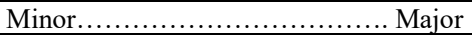 } & & \\
\hline & & & 1 & 2 & 3 & 4 & 5 & & \\
\hline Fewer contractor accidents & 23.1 & 0.0 & 7.7 & 0.0 & 23.1 & 23.1 & 23.1 & 3.70 & $1=$ \\
\hline Less impact on the environment & 23.1 & 0.0 & 15.4 & 0.0 & 0.0 & 38.5 & 23.1 & 3.70 & $1=$ \\
\hline Less complications & 7.7 & 7.7 & 7.7 & 7.7 & 30.8 & 23.1 & 15.4 & 3.08 & $3=$ \\
\hline Increased client satisfaction & 7.7 & 7.7 & 15.4 & 7.7 & 7.7 & 38.5 & 15.4 & 3.08 & $3=$ \\
\hline Improved contractor productivity & 7.7 & 0.0 & 15.4 & 23.1 & 23.1 & 15.4 & 15.4 & 2.92 & $5=$ \\
\hline Improved client performance (overall) & 7.7 & 7.7 & 15.4 & 7.7 & 23.1 & 23.1 & 15.4 & 2.92 & $5=$ \\
\hline Improved contractor quality / Less rework & 7.7 & 7.7 & 15.4 & 15.4 & 30.8 & 7.7 & 15.4 & 2.67 & $7=$ \\
\hline Less disruption of client process & 7.7 & 7.7 & 15.4 & 15.4 & 30.8 & 7.7 & 15.4 & 2.67 & $7=$ \\
\hline Improved contractor time (schedule) performance & 15.4 & 7.7 & 7.7 & 30.8 & 23.1 & 0.0 & 15.4 & 2.55 & 9 \\
\hline
\end{tabular}

Table 5 indicates the extent to which various aspects / interventions can contribute to an improvement in construction $\mathrm{H} \& \mathrm{~S}$ in terms of percentage responses to a scale of 1 (minor) to 5 (major), and a MS ranging between 1.00 and 5.00. $15 / 17(88.2 \%)$ MSs are above the midpoint score of 3.00, which indicates that in general the respondents can be deemed to perceive that the aspects / interventions can contribute to an improvement in construction H\&S. However, given that the MSs of the aspects / interventions ranked first to twelfth (70.6\%) are $>3.40 \leq 4.20$, the extent can be deemed to be between some extent to a near major / near major. The MSs of the aspects / interventions ranked joint thirteenth to seventeenth are $>2.60 \leq 3.40$ - between a near minor extent to some extent / some extent.

It is notable that aspects / interventions related to clients, designers, and contractors, and design, procurement, and construction all achieved MSs above the midpoint score of 3.00. Furthermore, the ranking achieved by H\&S, environmental, and quality management systems is notable - H\&S (1st); environmental (3rd), and quality (joint 6th). Client related aspects / interventions include H\&S, environmental, and quality management systems, and client actions / contributions. Designer related aspects / interventions include constructability reviews by designers, and prioritisation / consideration by designers. Contractor / construction related aspects / interventions include H\&S, environmental, and quality management systems, $H \& S$ programme, contractor programming, project specific plan for $H \& S$, and project specific plan for quality. Procurement related aspects / interventions include optimum project programme, prequalification of contractors on quality, contract documentation, integration of design and construction in terms of H\&S, pre-qualification of contractors on $\mathrm{H} \& \mathrm{~S}$, partnering, and choice of procurement system.

Table 5. Extent to which various aspects / interventions can contribute to an improvement in construction H\&S.

\begin{tabular}{|c|c|c|c|c|c|c|c|c|}
\hline \multirow{3}{*}{ Aspect / Intervention } & \multicolumn{6}{|c|}{ Response (\%) } & \multirow{3}{*}{ MS } & \multirow{3}{*}{ Rank } \\
\hline & \multirow{2}{*}{$\begin{array}{l}\text { Un- } \\
\text { sure }\end{array}$} & \multicolumn{5}{|c|}{ Minor........ } & & \\
\hline & & 1 & 2 & 3 & 4 & 5 & & \\
\hline H\&S Management System (H\&SMS) & 7.7 & 0.0 & 0.0 & 23.1 & 38.5 & 30.8 & 4.08 & 1 \\
\hline $\mathrm{H} \& \mathrm{~S}$ programme & 0.0 & 0.0 & 0.0 & 23.1 & 53.8 & 23.1 & 4.00 & 2 \\
\hline Environmental Management System (EMS) & 7.7 & 0.0 & 0.0 & 30.8 & 38.5 & 23.1 & 3.92 & $3=$ \\
\hline Contractor programming & 0.0 & 0.0 & 7.7 & 23.1 & 38.5 & 30.8 & 3.92 & $3=$ \\
\hline Project specific plan for $H \& S$ & 0.0 & 0.0 & 15.4 & 7.7 & 53.8 & 23.1 & 3.85 & 5 \\
\hline Pre-qualification of contractors on quality & 0.0 & 7.7 & 0.0 & 30.8 & 30.8 & 30.8 & 3.77 & $6=$ \\
\hline
\end{tabular}


John Smallwood / Proceedings of the Creative Construction Conference (2019) 090 https://doi.org/10.3311/CCC2019-090

\begin{tabular}{|c|c|c|c|c|c|c|c|c|}
\hline Optimum project programme & 0.0 & 7.7 & 0.0 & 23.1 & 46.2 & 23.1 & 3.77 & $6=$ \\
\hline Client actions / contributions & 0.0 & 7.7 & 0.0 & 30.8 & 30.8 & 30.8 & 3.77 & $6=$ \\
\hline Quality Management System (QMS) & 0.0 & 0.0 & 7.7 & 30.8 & 38.5 & 23.1 & 3.77 & $6=$ \\
\hline Contract documentation & 0.0 & 0.0 & 7.7 & 30.8 & 46.2 & 15.4 & 3.69 & $10=$ \\
\hline Project specific plan for quality & 0.0 & 0.0 & 15.4 & 23.1 & 38.5 & 23.1 & 3.69 & $10=$ \\
\hline Integration of design and construction in terms of $\mathrm{H} \& \mathrm{~S}$ & 0.0 & 7.7 & 7.7 & 30.8 & 38.5 & 15.4 & 3.46 & 12 \\
\hline Constructability reviews by designers & 0.0 & 0.0 & 15.4 & 38.5 & 38.5 & 7.7 & 3.38 & $13=$ \\
\hline Pre-qualification of contractors on $\mathrm{H} \& \mathrm{~S}$ & 0.0 & 15.4 & 7.7 & 23.1 & 30.8 & 23.1 & 3.38 & $13=$ \\
\hline Prioritisation / consideration by designers & 0.0 & 7.7 & 0.0 & 61.5 & 15.4 & 15.4 & 3.31 & 15 \\
\hline Partnering & 7.7 & 23.1 & 7.7 & 30.8 & 23.1 & 7.7 & 2.83 & 16 \\
\hline Choice of procurement system & 7.7 & 30.8 & 0.0 & 30.8 & 30.8 & 0.0 & 2.67 & 17 \\
\hline
\end{tabular}

\section{Conclusions}

The traditional project parameters of time, quality, and cost are more important than public H\&S and project H\&S. Given that public $H \& S$ is more important than project $H \& S$, it can be concluded that clients are more concerned with the public than the workforce. This conclusion is reinforced by the importance afforded construction ergonomics.

Given that the respondents' organisations can be deemed to have influenced and contributed to contractors' H\&S relative to a range of interventions / requirements, it can be concluded that clients do influence contractor H\&S. They do so directly through requiring contractors to participate in their H\&S activities, or compliance with their systems, and procedures, and indirectly through interventions that create an enabling environment.

Clients identified the role of a range of aspects in terms of their impact on H\&S. Therefore, it can be concluded that clients understand and appreciate the role of design, procurement, H\&S culture, management, H\&S training, and resources, in H\&S performance. This bodes well as such an understanding and appreciation is likely to reinforce their involvement in and contributions to contractor $\mathrm{H} \& \mathrm{~S}$, and possibly stimulate either intensification of or further involvement and contributions, or both.

Client organisations contend that they have influenced construction H\&S, and that they could influence construction H\&S more. Therefore, it can be concluded that clients do influence construction H\&S. Furthermore, the recognition that they could influence construction $\mathrm{H} \& \mathrm{~S}$ more, is also likely to reinforce their involvement, and possibly stimulate either intensification, or further involvement, or both.

Clients identified that a range of benefits accrue from their contributions to contractor H\&S. Therefore, it can be concluded $\mathrm{H} \& \mathrm{~S}$ plays a holistic role in project performance. Furthermore, from an investment perspective, clients have realised a return on their investment in contractor $\mathrm{H} \& \mathrm{~S}$. This in turn is also likely to reinforce their involvement, and possibly stimulate either intensification or further involvement, or both.

Clients identified that a range of design, procurement and construction aspects / interventions can contribute to an improvement in construction $\mathrm{H} \& \mathrm{~S}$. Therefore, it can be concluded that $\mathrm{H} \& \mathrm{~S}$ performance can be improved, and that all stakeholders can contribute to such an improvement.

\section{Recommendations}

H\&S should be included as a value on all projects, and afforded status at least equal to that afforded to cost, quality, and time. This can be achieved by the following primary interventions on all projects: the inclusion of H\&S during decision making all levels and during all reviews; project specific H\&S requirements; H\&S goals; the facilitating of optimum financial provision for $\mathrm{H} \& S$; the inclusion of $H \& S$ as a criterion for pre-qualification; the appointment of $\mathrm{H} \& \mathrm{~S}$ conscious project managers, designers, quantity surveyors, and contractors; the inclusion of H\&S as an agenda 
John Smallwood / Proceedings of the Creative Construction Conference (2019) 090

https://doi.org/10.3311/CCC2019-090

item for all meetings; project H\&S reporting in the form of 'leading' and 'lagging' indicators, and requiring of a project close out report which includes H\&S.

In addition, clients should create an enabling environment through the following: the implementation of an H\&S management system within which contractors and their supply chain can be managed; the selection of appropriate procurement systems, and the identification of optimum project durations.

Furthermore, clients should undertake direct and indirect interventions relative to contractor H\&S. Client provided H\&S induction and training constitutes direct interventions. Conducting constructability reviews and requiring contractor employee identification constitutes indirect interventions.

The SAPOA and professional associations should contribute to the realisation of optimum status being afforded to $\mathrm{H} \& \mathrm{~S}$ upon the revision of standard industry contract documentation. Public sector clients should include H\&S as a criterion when assessing tenders.

Tertiary education property related programmes should address construction H\&S and ergonomics, and SAPOA should evolve construction H\&S, and ergonomics practice notes. However, this should not be constrained to the property sector, but expanded to include construction project manager, designer, and quantity surveying tertiary education programmes, accompanied by interventions from the related professional associations. The role of all stakeholders should be addressed by all the respective disciplines.

\section{References}

[1] Construction Industry Development Board (cidb), Construction Health \& Safety in South Africa Status \& Recommendations, cidb, Pretoria, 2009.

[2] Republic of South Africa, No. R. 84 Occupational Health and Safety Act, 1993 Construction Regulations 2014. Government Gazette No. 37305 , Pretoria, 2014.

[3] International Labour Office (ILO), Safety and Health in Construction, ILO, Geneva, 1992.

[4] X. Huang, J. Hinze, Owner's Role in Construction Safety: Guidance Model, Journal of Construction Engineering and Management, February, 2006, 174-181. https://doi.org/10.1061/(ASCE)0733-9364(2006)132:2(174)

[5] Department of Education, Employment and Workplace Relations, The Model Client Framework The Model Client: Promoting Safe Construction, Commonwealth of Australia, Canberra, 2008.

[6] Health \& Safety Executive (HSE), Revitalising Health and Safety in Construction, HSE, London, 2002.

[7] J.W. Hinze, Construction Safety, 2nd edition, Prentice Hall Inc., New Jersey, 2006. 